\title{
Life threatening injuries to the chest caused by plastic bullets
}

\author{
A J Ritchie, J R P Gibbons
}

Department of

Cardiothoracic Surgery,

Royal Victoria Hospital,

Belfast BT12 6BA,

Northern Ireland

A J Ritchie, FRCSI, surgical registrar

J R P Gibbons, FRCS, consultant cardiothoracic surgeon

Correspondence to: Mr Ritchie.

BrMed f 1990;301:1027
Plastic bullets have been available to police forces in the United Kingdom since $1988^{1}$ but have been used to control public disorder and riots in Northern Ireland since 1975. They were intended to be more accurate and no more damaging than the rubber bullet that they replaced. ${ }^{2}$ They are unique in that they are fired to inflict non-penetrating blunt trauma in an effort to immobilise rather than kill. Over 54000 rounds were fired during the 13 years of this study from 1975 . In this time 80 patients presented to hospitals in Belfast with injuries to the chest caused by plastic bullets. We assessed the outcome of these injuries.

\section{Patients and management}

Data on patients were obtained retrospectively from admission notes. Four patients died, three as a result of ventricular fibrillation precipitated by myocardial contusion and the other from haemopneumothorax and cardiac tamponade. Thirty five patients were admitted to hospital (19 with serious injuries and 16 with only soft tissue injuries). Three of those with serious injuries required ventilation and intensive care to treat pulmonary contusion. Four patients had myocardial infarction, of whom one required inotropic support. Four patients were treated for a combination of rib fracture, pneumothorax, and pulmonary contusion; three required chest drainage and two required ventilatory support. Eleven patients had soft tissue injuries in association with fractures; eight had a total of 18 rib fractures, two had a fracture of the sternum, and one had a fracture of a vertebral body; one required ventilatory support.

Fifty seven patients had only soft tissue injuries. Of these, 16 were admitted for observation, of whom five developed pulmonary contusion between the second and eighth days after admission, 21 were treated for their injuries then discharged, and 20 declined admission. Ten patients developed complications from retention of sputum.

Nineteen of those who died or were seriously injured had been struck in the anterior or left chest wall. All the patients whom we traced for follow up had recovered from their injuries completely.

\section{Comment}

The only other report comparing injuries from rubber and plastic bullets came from our hospital; it reported on 10 patients who had sustained non-serious chest injury. ${ }^{2}$

Guns that fire plastic bullets discharge a $10 \times 3.7 \mathrm{~cm}$ Teflon missile weighing $135 \mathrm{~g}$ at low muzzle velocity. The bullets tend to travel on their long axis to hit their target end on. This delivers the maximum kinetic energy to a small area of the chest wall and creates the so called "target lesion." The velocity at impact and the anatomical site seem to be the most important factors in chest injury.

We noted an increased incidence of death and serious injury among patients struck in the anterior and left chest. The shock wave generates shearing stresses between structures of different densities. In the soft tissue and bones of the chest wall direct compression causes contusion and fracture. Internally, the wave is transmitted to more dense and fixed mediastinal structures, causing myocardial contusion, infarction, and tamponade; in the fluid-air interphase of the lung, gases that are initially compressed suddenly re-expand as the shock wave travels on, leading to alveolar rupture, which if it is of sufficient magnitude may impair oxygenation. ${ }^{3}$

We believe that all injuries to the chest caused by plastic bullets should be regarded as potentially life threatening. We recommend that all patients be admitted to hospital so that cardiac monitoring and enzyme state can be determined; chest radiography be repeated after a period of observation to detect haemopneumothorax and pulmonary contusion, which may present insidiously even in the absence of fracture; and adequate analgesia be prescribed to prevent the secondary complications of retention of sputum.

We thank Miss May Weller for typing the manuscript.

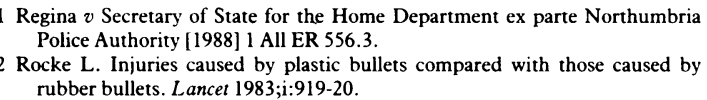

(Accepted 14 August 1990)

\section{Correction}

Risk of disability and mortality due to overweight in a Finnish population

An editorial error occurred in this paper by Dr Aila Rissanen et al (13 October, p 836). The legend to the caption should read "Age adjusted rates of work disability $(-)$ and mortality $(--)$ in women $(\bullet)$ and men (0)," not "work disability (..-) and mortality $(-)$ as published.

\section{ONE HUNDRED YEARS AGO}

The decision of the Metropolitan Public Gardens Association to close nine of the small gardens and playgrounds laid out under their care and at their cost, is one much to be regretted in the public interest, but as to which they seem to have little alternative. The resources of the Association do not allow it to meet permanently the annual cost of maintenance of the large number of playgrounds which through their instrumentality have been made available for the population of London. They have also regarded it as their task to secure the consent of the owners to the dedication to public use of these places, to take the necessary steps, and to procure the funds for laying them out, and to pay the cost of caretakers and general maintenance for a limited number of years. After having thus demonstrated the utility and value of such grounds, they have, as a rule, been successful in inducing the local authorities to take upon themselves the relatively small annua expenditure for maintenance of places so eminently useful for the poorer population of the locality. In the nine or ten cases in which this has not been found possible, they appealed to the London County Council to take upon themselves this burden. That course was recommended by the Open Spaces Committee, but the Council, by an evenly divided vote, has deferred, if not rejected, the proposal of its Committee, on the ground apparently that the Council, like the law, de minimis non curat, and probably, also, for the reason that it is the especial duty and within the means of each locality to do for itself what for the most part the local authorities have been willing to do. The difficult position is apparent, but it may be hoped that a solution will be found either in the indulgence of the Council, or from the munificence of individuals, and that spaces so conducive to the happiness and welfare of the population, who have shown themselves so thoroughly capable of enjoying them and putting them to good uses, will not be permanently closed against them after being dedicated to their use and appropriated for their recreation.

(British Medical fournal 1890;i:971.) 